\title{
Uma leitura das imagens da subversão do Direito no Livro I da Farsália, de Lucano
}

\author{
Francis Willams Brito da Conceição ${ }^{i}$ \\ Hermes Orígenes Duarte Vieira ${ }^{\text {ii }}$
}

\begin{abstract}
Resumo: A Farsália, também conhecida como Bellum Civile, é um poema épico escrito por Lucano no século I d. C. A epopeia, escrita in media res, isto é, em meio aos acontecimentos, narra uma sucessão de episódios da Guerra Civil travada entre César e Pompeu. Portanto, realizaremos uma análise acerca das imagens da subversão do direito, baseado nos seguintes: os versos 1-10, 35-40, 171-182, do livro I da Farsália. A problemática que visamos responder é como a subversão das leis e suas imagens favorecem os interesses de poder dos generais no livro I da Farsália. Assim, esperamos entender como a Guerra Civil ganha um caráter superlativo por designar fatos bélicos que extrapolam a civilidade, visto que os detentores do poder subvertem o direito por objetivarem a manutenção de seus interesses de poder. Para tanto, utilizaremos o aporte teórico de Alves (2018), Coulanges (2006), García (2006), Grimal (2014), Vieira (2018), entre outros.
\end{abstract}

Palavras-chave: Literatura Latina. Lucano. Bellum Civile.

\section{A reading of subversion images of the law in Lucan's Pharsalia, book I}

\begin{abstract}
The Pharsalia, also known as Bellum Civile, is an epic poem written by Lucan in the 1st century AD. The epic, that begins in medias res, i. e., in the midst of the events, narrates a succession of episodes of the Civil War fought between Caesar and Pompey. Therefore, we will make an analysis of the subversion of law images, based on the following excerpts: verses 1-10, 35-40, 171-182, from the book I of Pharsalia. The problem we aim to solve is how the subversion of laws and of its images favor the power interests of the generals in the book I of Pharsalia. Thus, we hope to understand how the Civil War gains a superlative character by designating warlike facts that go beyond civility - since the power holders subvert the right because of their objective of maintaining their power interests. To this end, we will use the theoretical inputs of Alves (2018), Coulanges (2006), García (2006), Grimal (2014), Vieira (2018), and others.
\end{abstract}

Keywords: Latin Literature. Lucan. Bellum Civile.

Submetido em: 12 out. 2019

Aprovado em: 12 nov. 2019

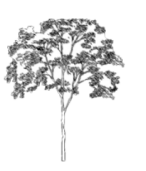

\author{
(c) EY-sA \\ Esta obra está licenciada com uma Licença Creative Commons \\ Compartilha Igual 4.0 Internacional \\ DLCV - Língua, Linguística \& Literatura
}

ISSN 1679-6101

EISSN 2237-0900

\footnotetext{
${ }^{\text {i }}$ Mestrando em Letras pelo Programa de Pós-graduação em Letras (PPGL) da Universidade Federal da Paraíba (UFPB). E-mail: franciswillams1@gmail.com

ii Doutor em Letras (UFPB) e Professor de Línguas e Literaturas Clássicas do Departamento de Letras Clássicas e Vernáculas (DLCV/UFPB). E-mail: hermesorigenes@gmail.com
} 
Heu quantum terrae potuit pelagique parari Hoc, quem civiles hauserunt, sanguine, dextrae...

Tunc, si tantus amor belli tibi, Roma, nefandi,

Totum sub Latias leges cum miseris orbem, In te verte manus: nondum tibi defuit hostis. ${ }^{l}$

(Lucano)

\section{INTRODUÇÃO}

A Farsália, de Lucano, canta uma guerra civil ${ }^{2}$ travada entre romanos, liderados por César e Pompeu, que ocorreu em Farsalo, no ano 48 a.C. Portanto, o poema não se baseia numa tradição mítica, como observamos em outros escritos épicos da Antiguidade Clássica ${ }^{3}$, o que faz com que a Farsália, também conhecida como Bellum Civile, figure como um texto que promove uma espécie de rompimento com a tradição vigente no estilo épico Clássico, a exemplo da epopeia virgiliana, Eneida. Assim, o poeta recupera, de forma literária e, de certa forma, histórica, a glória romana e sua ruína por submeter-se ao seu próprio jugo destruidor, por meio da autodestruição, pois, como bem indica o poeta, o texto trata de um "povo poderoso que ergueu contra si próprio seu poder vitorioso." (LUCANO, I, v. 2-3, tradução nossa) $)^{4}$.

Sendo assim, objetivamos, neste trabalho, realizar uma análise acerca da subversão do direito e das reverberações dessa prática social presente na superfície do texto literário, debruçando-nos sobre o estudo do livro I, mais especificamente sobre os excertos compreendidos entre os versos de 1-10, de 35-40, e de 171-182. O interesse em abordar as imagens e ações presentes no poema dá-se pela necessidade de se discutir a teoria da subversão ${ }^{5}$ aliada às noções de Direito Romano, a partir da quebra da civilidade legal pela

\footnotetext{
1 “Ah! Quanto de terra e mar poderia ter sido obtido,/ com esse sangue que as destras civis absorveram.../ Se tens tamanho amor de guerra nefanda, Roma,/ então mesmo quando tiverdes lançado todo o mundo sob as leis do Lácio,/ dirige as mãos contra ti: ainda assim não te faltou inimigos." (LUCANO, I, v. 13-14, 21-23, tradução nossa).

${ }^{2}$ Segundo Vieira (2018, p. 6-7), é a Guerra Civil protagonizada pelos partidários de César e Pompeu, que precedeu a queda da República Romana, e teve César como vencedor; ocorreu em Fársalo, na Tessália, por volta do ano 48 a. C.

${ }^{3}$ A exemplo da Ilíada, de Homero, e da Eneida, de Virgílio.

${ }^{4}$ A tradução dos versos utilizados como corpus para este trabalho é de responsabilidade dos autores, constituindo-se uma tradução instrumental. Cf. Verso original: "populunque potentem/In sua victrici conversum viscera dextra".

${ }^{5}$ Entendemos que a teoria da subversão consiste em um campo de estudos que se dedica à fenomenologia da guerra subversiva, isto é, ao mapeamento e problematização das formas de conflitos, quer políticos quer sociais, ocorridos em um dado território. Segundo Garcia (2006, p. 171), trata-se de uma "luta conduzida no interior de um dado território, por uma parte dos seus habitantes, ajudados e reforçados ou não do exterior, contra as autoridades de direito e de facto estabelecidas, com a finalidade de lhes retirar o controlo desse território ou, pelo menos, de paralisar a sua ação".
} 
institucionalização do crime estatal, consequência da expansão territorial de Roma. Em outra instância, o que justifica a investigação dessa abordagem temática pode sintetizar-se por meio do famoso verso inicial da Farsália: "o direito dado ao crime" (LUCANO, I, v.2, tradução nossa) ${ }^{6}$; pois ele, de alguma maneira, traduz o aglomerado de ideias de criminalidade (leia-se criminalidade como agrupamento de crimes e impiedades notados no âmbito da sociedade civil) presentes no texto.

Destarte, as imagens do "direito dado ao crime" ganham corporeidade ao longo da narrativa, conforme explicitado no fragmento: "o próprio crime e o nefas ${ }^{7} /$ agradam esta paga" (I, v. 38-39, tradução nossa) ${ }^{8}$, que nos mostra que o sangue cartaginês é uma consequência, ou recompensa, do crime e da iniquidade. As reverberações desses fatos acontecem em forma de ações negativas para o contexto romano, prerrogativas que nós denominamos de "imagens da subversão do direito". Observamos que a representação da pátria, em uma epifania a César, figura a real situação de Roma e a corrupção do povo em consequência da injustiça naturalizada (LUCANO, I, v. 174, tradução nossa), trazendo à luz condições que atingem a honra da pátria, através da coerção das leis e do usufruto destas em benefícios alheios ao interesse popular. Nesse sentido, notamos que a violação das leis se faz crescente nos desencadeamentos das ações poéticas da Farsália, uma vez que o próprio César, no seu discurso em Hespéria, diz: “Aqui, deixo a paz e as leis violadas” (LUCANO, I, v. 225$)^{9}$.

Percebemos ainda uma segunda figuração dessa subversão: o "direito subjugado" pelo silenciamento das leis, que deveriam promover a estabilidade dos cidadãos, mas acabam fomentando a expatriação e o exílio. Apresenta-se-nos, a partir dos versos 277-279, do livro I, a imagem, através da personificação da lei emudecida, quando é dito: "Mas, as leis, pela guerra forçadas, silenciam" 10 . Por fim, temos a símile descrita nos discursos augurais de Arrunte e Fígulo, que, a partir de simbologia das vísceras de um touro ofertado em sacrifício a Baco, personifica uma subversão, através do ato de trocas das vísceras.

\footnotetext{
6 Cf. Verso original: "Iusque datum sceleri canimus".

7 Alves (2018, p. 110) estabelece uma diferença tomada historicamente no campo das concepções do direito romano: os significados de ius e fas. Para o autor, ius está historicamente ligado a uma noção de direito objetivo, enquanto fas refere-se ao direito subjetivo, que atua na esfera do direito sagrado ("leges sacratae"/ leis sagradas), relacionando-se à religião doméstica. Nesse sentido, com o passar do tempo é que, no âmbito do direito público, ius vai se sobrepondo ao fas, tornando a influência deste menos abrangente. Por outro lado, Vieira (2018) aponta para o vocábulo nefas como um substantivo que nega o fas, tornando-o, portanto, ímpio, criminoso e sacrílego por ser contrário à lei divina (faz oposição à expressão da vontade dos deuses) e às leis da religião e da natureza.

${ }^{8}$ Cf. Verso original: "scelera ipsa nefasque/ Hac mercede placent".

${ }^{9} \mathrm{Cf}$. verso original: "hic pacem temerataque iura relinquo".

${ }^{10}$ Cf. Verso original: "Sed [...] leges bello siluere coactae".
} 
Diante do exposto, investigamos as seguintes imagens do livro I da Farsália: a) a pátria decrépita e em desespero; b) as leis emudecidas pela coerção das guerras e dos interesses políticos; c) o povo prostrado pelo rigor injusto da lei dada ao crime, na qual o correto está estagnado e o incerto funciona a todo vapor, como podemos observar na cena do fígado bipartido do touro: o fígado, cuja parte putrefata, empapada e cheia de pus, funcionava, ao passo em que a parte não afetada apresentava-se esguia - esses símbolos podem ser vistos como signos metafóricos que apontam, possivelmente, para as consequências que a guerra "mais que civil", plus quam civila (v. 1), trazia aos romanos, pelo próprio processo de autodestruição que ocorria entre eles).

Para desenvolvermos as análises, nos baseamos nas definições metodológicas apresentadas por Marconi e Lakatos (2017) para caracterizar esse trabalho como uma pesquisa bibliográfica, pois se trata de uma forma específica de produção de conhecimento, que se utiliza da consulta a materiais teóricos para desenvolver-se. Desse modo, empregamos o método de abordagem do tipo indutivo, uma vez que partimos do estudo de uma categoria estrutural "enredo", no livro I da Guerra Civil, para uma temática, e de caráter social, que é a subversão do direito, um tema mais centralmente discutido pela Sociologia do Direito e pelos Estudos Culturais.

Segundo Marconi e Lakatos (2017, p. 108), “os métodos de procedimento seriam etapas mais concretas da investigação, com a finalidade mais restrita em termos de explicação geral", objetivando o esclarecimento do corpus em andamento. Por esta razão, escolhemos uma categoria temática, a subversão do direito, a fim de que a análise literária respondesse a alguns questionamentos, a saber: como a subversão do direito aparece na Farsália? De que maneira essa categoria temática é abordada no texto literário de Lucano? Pode-se confirmar que tais imagens apresentam-se a partir de um novo modo de abordagem, ou elas dão continuidade à forma empregada por outros escritores da tradição épica Greco-latina?

Para apresentarmos as possíveis respostas a tais questionamentos, utilizamos História do Direito Romano, de José Carlos Moreira Alves (2018) e Teoria do Fenômeno Subversivo, de Francisco Proença Garcia (2006), possibilitando a interface entre as etapas da subversão, isto é, desmoralização, desestabilização, crise e normalização; e as imagens do direito dado ao crime, apresentadas por Lucano. Portanto, dividimos a pesquisa em duas fases: na primeira, elencamos as diversas menções à ideia de direito dado crime, numa espécie de levantamento discursivo em diálogo com a mentalidade histórica de Direito Romano discutida por Alves (2018); na segunda, analisamos os fragmentos textuais em que as imagens subversivas são 
recorrentes, mostrando como ocorre o processo, ou o fenômeno, de subversão do direito, a partir da teoria de Garcia (2006).

\section{IMAGENS DA SUBVERSÃO DO DIREITO NA EPOPEIA GRECO-LATINA}

Apesar de os deuses não serem enquadrados por leis humanas, por estas serem vinculadas ao mundo dos mortais, as divindades Greco-latinas estavam sob o imperativo da $\theta \varepsilon \mu^{\prime} \varsigma_{\varsigma}{ }^{11}$, lei divina que regia o cosmo e se fazia predominante entre deuses e mortais; havendo uma diferenciação entre essa esfera divina e o que, posteriormente, se denominou $\delta i \kappa \eta^{12}$, a lei dos homens. Sendo assim, tais deuses podem, também, ser estudados como categorias literárias, isto é, personagens lidas através das análises previstas pelas frentes temáticas ou teóricas, embora não estejam submetidas a elas, pertencendo ao âmbito do imaginário míticoreligioso e cultural Greco-latino. Os mortais cometem crimes e são, a depender do momento histórico em que estiverem inseridos, julgados pelas leis civis ou pelas leis dos deuses, que não se dissociam da tradição legal da cidade. Entretanto, os deuses não devem ser lidos por essa perspectiva, como se sujeitos fossem às leis humanas; igualmente, devem ser analisados a partir de uma perspectiva teogônica e oriunda de um ambiente de consciência mítica, sem intercorrências anacrônicas.

Partindo desses pressupostos, os deuses podem cometer desmedidas que interrompem a harmonia do cosmo e, quando isso ocorre, eles são punidos. Há uma vontade cósmica que, na tradição mítica, foi incumbida a Zeus; por isso, ele age como mantenedor da harmonia da natureza e, não raro, funciona como agente intermediador dos problemas causados pelos deuses. Assim, podemos conceber que o erro divino só é punido se afetar a ordenação cosmológica. Se tomarmos como exemplo alguns episódios da Teogonia, de Hesíodo, notamos que: ora, o poeta narra a desmedida natural de Urano, quando ele impede que os filhos saiam do ventre de Gaia, que copulava incessantemente, "tão logo cada um deles nascia/ a todos ocultava, à luz não os permitindo,/ na cova da terra" (HESÍODO, v. 156-

\footnotetext{
${ }^{11} \theta$ Ém (Témis): segundo Grimal (2014, p. 435), é "a deusa da Lei, pertence à raça dos Titãs. É fillha de Urano e Geia e irmã das Titânides. Como deusa das leis eternas, figura entre as esposas de Zeus, a segunda depois de

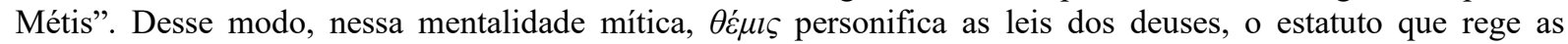
relações entre as divindades.

${ }^{12}$ No Vox, Diccionario Manual Griego: Griego Clásico-Español, esse termo é apresentado como "costume, uso, justiça" (tradução nossa), sendo estes os conceitos mais usuais para o vocábulo. Assim sendo, para tradição cultural greco-latina, refere-se aos códigos que regiam as relações sociais entre os humanos, que se estabeleciam com um caráter consuetudinário. Nesse sentido, o conceito assume uma carga de oposição à Témis, não no sentido de contrariar ou invalidar as leis dos deuses, mas de constituir-se como as leis humanas, e, portanto, profanas, em relação às leis divinas, consideradas sagradas, conforme afirmam Coulanges (2006, p. 295-296) e Alves (2018, p. 110).
} 
158) ${ }^{13}$; ora, observamos uma desmedida na relação entre Cronos e Reia, visto que ele age de encontro ao que fora previsto pelos fados e em prol de distanciar-se do oráculo que indica que um de seus filhos irá excedê-lo em força e destroná-lo.

$\mathrm{O}$ direito à vida era um princípio de distanciamento do Caos, uma vez que, a cada momento que se disseminava e havia a geração de deuses e mortais, o universo caminhava ainda mais para organização e diferenciação. Assim sendo, o canibalismo de Crono pode ser, simbolicamente, lido como uma subversão do direito à vida, uma tentativa de retorno ao Caos ou ao que Ovídio, denominou de "massa confusa e informe, apenas peso inerte, amálgama discordante de elementos mal unidos" (Metamorfoses, I, v. 7-9) ${ }^{14}$. Observamos, na Teogonia, o estabelecimento de princípios e leis que faziam parte da consolidação das linhagens divinas.

Para tanto, a fim de que a situação acima mencionada fosse desfeita, Reia, prestes a parir Zeus, suplica aos seus pais, Terra e Céu que desenvolvam um ardil para que ela parisse longe dos olhos de Crono. Urano e Gaia a atenderam e levaram Zeus para ser criado e nutrido na ilha de Creta. Posteriormente, encueirou-se uma pedra para que Crono a engolisse. Com esse fato, Crono vomitou a grande pedra e, depois, seus tios paternos - os Titãs, os Ciclopes e os Centímanos (HESÍODO, v. 453-506). Esses episódios nos mostram a necessidade do direito à vida na ordenação do Caos; tanto que, quando Zeus derrota Crono, destarte, assume a manutenção da ordem e restabelece o cosmo, criam-se os princípios e as atuações dos deuses, que, posteriormente, foram chamados olímpicos e compuseram o Panteão de deuses gregos, a partir de uma organização distributiva de honras e funções, objetivando não retornar ao Caos primordial. Podemos, então, ler essa cena de Crono como uma forma de subverter o direito à vida, não se baseando em uma premissa de poder distribuído como acontece no principado de Zeus.

\section{IMAGENS DA SUBVERSÃO DO DIREITO NO LIVRO I DA FARSÁLIA}

No livro I da Farsália, há inúmeros trechos em que se vislumbram discursos narrativos que rementem diretamente ao fenômeno da subversão do direito, retomados por figuras literárias, tais como a prosopopeia e o símile, que, de alguma forma, explicitam o caráter drástico das consequências da Guerra Civil - como a significação criada pelo excerto:

\footnotetext{
13 Tradução de JAA Torrano (1995).

${ }^{14}$ Cf. Referências. Tradução de Domingos Lucas Dias (2017), do trecho: "Rudis indigestaque moles/ nec quidquam nisi pondus iners congestaque eodem/ non bene iunctarum discordia semina rerum".
} 
"tudo dá, quem nega aquilo que é justo" (LUCANO, I, v. 349) ${ }^{15}$. Consideramos esse fragmento ser o pressuposto subordinador do direito dado ao crime, uma vez que ele realiza a polaridade circunstancial entre o que é tido como justo, isto é, o direito negado por concessão estatal, e o injusto, que é o direito dado à subversão do direito máximo: o de ter o próprio direito, sendo este tomado do povo e entregue aos interesses de uma guerra "mais que civil".

Todavia, na seção seguinte, enfatizaremos as três imagens elencadas no texto literário, a partir de um caráter simbólico: a epifania da pátria personificada, abordando os excertos compreendidos entre os versos 183-205; o silenciamento das leis, que está no plano figurativo da linguagem, quando o poeta se utiliza do recurso da personificação para apresentar as condições sociais e políticas das leis romanas, usando os versos 273-279; e a imagem das predições de Fígulo e Arrunte, sacerdotes romanos, que se encaixa no âmbito da simbologia do augúrio, prática recorrente que se interligava aos cenários político e religioso.

\section{NA EPIFANIA SIMBÓLICA DA PÁTRIA A CÉSAR (V. 183-205)}

O termo Epifania, do grego $\varepsilon \pi \iota \varphi \alpha ́ v \varepsilon \imath \alpha^{16}$, é um substantivo feminino intimamente ligado à concepção da aparição divina aos que lhes eram queridos, como heróis e sacerdotes, conforme podemos observar na literatura greco-latina, a exemplo do Canto I da Ilíada, de Homero, quando Atenas aparece para impedir Aquiles de cometer uma hybris ${ }^{17}$. No entanto, após o advento do Cristianismo e a ressignificação de ideias como o politeísmo, as imagens epifânicas saíram do estrito âmbito religioso e assumiram o lugar de categoria literária.

Contudo, podemos indicar que, geralmente, as manifestações epifânicas seguem uma sequência de atos: a divindade se apresenta em sua forma corpórea, porém apenas o avisado pode presenciar; diz palavras divinas com o intuito de aconselhá-lo acerca de um evento relevante; o avisado reconhece a divindade por meio de um sinal, a exemplo de Aquiles, que reconheceu Atena através dos olhos faiscantes da deusa. Tudo isso acontece, nesse caso, para que ele não cometa uma desmedida. O herói Pelida ${ }^{18}$ sabe que, aqueles que obedecem aos deuses, serão atendidos em seus pedidos; assim, Aquiles atende ao conselho de Atena (Ilíada, I, v. 190- 220) ${ }^{19}$.

\footnotetext{
${ }^{15}$ Cf. Verso original: Omnia dat, qui iusta negat.

${ }^{16} \mathrm{O}$ vocábulo $\varepsilon \pi \imath \varphi \alpha ́ v \varepsilon l \alpha$ (epiphaneia), substantivo feminino da primeira declinação com tema em (- $\alpha$ puro), aparece no Vox, Diccionario Manual Griego: Griego Clásico-Español, como "aparição, manifestação, epifania" (tradução nossa).

${ }^{17}$ Para Grimal (2014, p. 227), a 'Y $\beta \rho \iota \varsigma$ (hybris) consiste em uma “abstração, a personificação do Exagero e da Insolência".

${ }^{18}$ Referência a Aquiles, filho de Peleu e da deusa Tétis. Por isso, o uso do epíteto Pelida para aludir ao nome do pai, Peleu, e a sua genealogia. Cf. Ilíada (Canto I, v. 1, tradução de Carlos Alberto Nunes).

19 Tradução de Frederico Lourenço (2013).
} 
Na Eneida, de Virgílio, também encontramos um momento de epifania do herói: quando Eneias, tomado pela fúria, maquina planos de assassinar a fillha de Tíndaro e, estando ele determinado a executar o intento, apresenta-se um brilho celeste clareando toda noite e o herói consegue visualizar a deusa Vênus, sua mãe, que lhe mostra o verdadeiro motivo da destruição de Troia (Eneida, II, v. 588-604) ${ }^{20}$.

Podemos mencionar, ainda, que, a partir das lições apresentadas na aparição de Vênus a Eneias, há uma possível relação entre epifania e Pensamento Estoico ${ }^{21}$, pois a deusa mostra ao herói que, contra o fado, ninguém pode se opor, sem que antes sofra as devidas consequências, e que, portanto, ele deveria direcionar suas energias ao verdadeiro objetivo de sua vida: fundar as bases para uma Nova Troia.

No entanto, a Epifania da pátria a César, na Farsália, apresenta um enredo um pouco distinto das aparições divinas aludidas acima, porque não é uma divindade que aparece para seu apadrinhado. No caso da Farsália, entre os versos 183 e 205 do livro I, presenciamos o seguinte itinerário: em primeiro lugar, é uma epifania simbólica, em que a pátria, por meio de um símile, apresenta-se a César em uma imagem que figura, exata e diagnosticamente, o caos pelo qual Roma passava no contexto da Guerra Civil.

A pátria surge para César totalmente decrépita, com voz trêmula, cabelos brancos, e um retrato bem desfigurado, interrogando-lhe a respeito de seu destino (v.190). A pergunta soa como um requisito de finalidade, pois seu sentido prefigura o objetivo das epifanias: postular um determinado limite a "um herói", impedindo que ele cometa uma desmedida. Vale ressaltar que, na Ilíada, o estabelecimento do limite visa ao não cometimento da hybris por Aquiles, uma vez que, sem a interferência da deusa, ele mataria a Agamemnon; já na Farsália, o limite da epifania simbólica evita - ou, pelo menos, tenta evitar -, a execução de uma desmedida sociopolítica, através de uma barreira geográfica que inibia a ultrapassagem do Rubicão ${ }^{22}$, ato que representaria, para César, a desonra e a falta de civilidade, visto que seria a quebra do linde imposto a qualquer cidadão.

\footnotetext{
${ }^{20}$ Tradução de Carlos Alberto Nunes (2016).

${ }^{21}$ Pensamento Estoico ou, segundo Ullmann (2008), Filosofia Estoica refere-se a um conjunto de concepções de ordem da fenomenologia da natureza (filosofia da natureza), defendido por alguns filósofos da chamada Escola Filosófica Helenística. Tal pensamento divide-se em três fases: o Estoicismo Primitivo, que tinha como representantes Zenon de Cítio, Cleantes e Crisipo (século III a. C.); o Estoicismo Médio, com Panécio e Posidônio; e o Estoicismo Romano, com nomes mais conhecidos, como Sêneca e Marco Aurélio. Dentre as concepções estoicas da natureza - como a finitude do mundo, os quatro reinos da natureza, a conflagração universal - temos a ideia de fatum, que consiste na percepção de que todos os acontecimentos estão diretamente ligados a uma determinação do destino. É exatamente a essa concepção que nos referimos aqui nessa menção.

${ }^{22}$ Segundo Vieira (2018, p. 41-42), trata-se de um pequeno Rio localizado ao Sul de Ravena e que, antes de Augusto, estabelecia os limites entre Roma e Gália.
} 
Segundo Garcia (2006, p. 171-172): “A Guerra Subversiva, que se inicia antes de se evidenciarem as suas manifestações violentas, subordina-se, em regra, a uma ideologia política de um grupo organizado", constituindo-se a primeira etapa do fenômeno subversivo, denominada de Período Pré-insurrecional (GARCÍA, 2006); essa fase começa muito antes de quaisquer propostas que evidenciem a Guerra Subversiva propriamente dita; caracteriza-se, antes, pela (in)subordinação de uma ideologia: quando César, decididamente, atravessara o Rubicão, ultrapassando os limites impostos pela organização político-militar romana. Ele estava, simbolicamente, iniciando o ato subversivo em si, que traria as consequências sociais e políticas narradas, por Lucano, no livro I.

Então, notamos que a epifania simbólica da pátria a César está relacionada a uma etapa prévia da subversão do direito. A ultrapassagem constitui-se da quebra da civilidade e, consequentemente, da alienação de um direito limítrofe considerado coletivo. No entanto, César optou por seguir seus desejos e avançar em seus propósitos, não dando ouvidos aos prenúncios dados pela pátria. Torna-se evidente, ainda, que a imagem de Roma não é mais aquela pungente, gloriosa, que se tinha antes da Guerra Civil, mas, sim, está abatida, chorosa e decrépita. Toda essa alegoria possivelmente representa o verdadeiro estado de Roma, que não suportou a si mesma.

\section{NA FIGURA DO EMUDECIMENTO DAS LEIS (V. 273-279)}

A lei, para os cidadãos greco-latinos, não se distinguia de suas práticas religiosas, uma vez que, segundo Coulanges (2006, p. 289), “os antigos códigos das cidades eram um conjunto de ritos, de prescrições litúrgicas, de preces, ao mesmo tempo em que de disposições legislativas". Sendo assim, concebemos que as relações entre os homens eram permeadas por esse não desmembramento entre lei e religião, fazendo com que os indivíduos honrassem as leis, por questões de piedade e por tradições civis, pois "quase não havia nenhum ato da vida que não tivesse relação com a religião" (COULANGES, 2006, p. 291). ${ }^{23}$

Assim sendo, quando tratamos de leis, estamos nos remetendo à forma basilar de mediações entre homens, tanto no âmbito religioso como no civil. Apesar de Lucano não seguir a tradição épica virgiliana, tampouco a tradição grega de vincular o andamento do enredo aos desígnios dos deuses pátrios e protetores das cidades, não podemos afirmar que sua obra está dissociada dos paradigmas religiosos da época, visto que acontecem constantes

\footnotetext{
${ }^{23}$ Tradução de Frederico Ozanam Pessoa de Barros.
} 
menções aos rituais de sacrifícios às divindades, a exemplo do culto a Baco e as atividades presságicas de determinados sacerdotes.

Por isso, quando há a subversão do direito pela Guerra Civil, há um problema social grave: quebram-se os princípios mediadores das relações humanas, justamente pelo silenciamento da lei que, no decorrer da guerra, está a serviço de interesses políticos de César e Pompeu. Logo, desenvolveremos uma leitura dessa imagem da lei silenciada dentro do poema épico: visto que seu emudecimento resultou na autodestruição de Roma e o povo, que era glorioso, ingressou em uma guerra fratricida, gerando um crime universal (v.6).

O trecho que analisamos está inserido em um discurso do tribuno Curião, que estava preocupado com o exílio dos tribunos discordantes da cidade (v. 266). Os versos 277-279 possuem uma sequência para análise: a) a guerra coage a lei para cumprir uma função que não é sua; b) a lei, exatamente por isso, emudece; c) o resultado desse emudecimento é o exílio de cidadãos romanos.

Segundo Garcia (2016), as guerras civis assumem caráter subversivo quando sua magnitude é interna, disseminando-se a partir de alianças feitas entre as massas formadas por cidadãos inconformados com a situação de estilhaçamento das autoridades políticas/civis e os grupos responsáveis pela polarização das leis, cujo objetivo aparece em detrimento à unidade e à dignidade de tais cidadãos. É justamente o que podemos perceber, em: "Mas depois que as leis, coagidas pela guerra, emudecerem,/ somos expulsos dos pátrios lares e nós, querendo, sofremos / o exílio: a tua vitória nos fará cidadãos" (LUCANO, I, v. 277-279)²4.

A guerra coage a lei a pavimentar o caminho de César, dirimindo os obstáculos que dificultassem tal fim. Notamos que a lei está cumprindo uma função que não lhe é própria, e, para isso, havia a comunhão com os senadores, e, quando estes se recusavam a tal, por medo dos decretos de guerra (v. 485-490), o aliado Curião fazia uso da tribuna para persuasão (v. 273-276).

Quando a medida para a lei é a forca (v. 176), têm-se os seguintes prejuízos: o direito aos preços igualitários é arrebatado pelos preços altos; ataques por crimes de usura, juros elevados, falta de crédito para população, entre outros (v. 180-182). O resultado de tudo isso reflete na expatriação dos cidadãos, com ou sem assentimento, atitudes que se desenvolvem longe dos acordos civis e próximas dos espaços onde "a paz e a lei [são] violadas" (v. 225227, tradução e grifos nossos).

${ }^{24}$ Cf. Versos originais: "Sed postquam leges bello siluere coactae,/ Pellimur e patriis laribus, patimurque volentes/ Exsilium: tua nos faciet victoria cives". 
NOS AUGÚRIOS DE ARRUNTE ${ }^{25}$ : AS VÍSCERAS SUBVERTIDAS NO SACRIFÍCIO A BACO (V. 605- 638)

O mundo greco-latino é permeado por uma perspectiva religiosa, que se baseia em dispositivos de caráter escatológico, ou, no sentido literário, proléptico. Por isso, os indivíduos recorrem constantemente ao auxílio dos deuses ou de seus sacerdotes. Os deuses são, em geral, responsáveis por enviar mensagens presságicas, objetivando deixar seus protegidos avisados acerca de uma situação inesperada. Os augúrios de Arrunte prenunciam a verdadeira situação social de Roma, bem retratada na imagem do sacrifício a Baco: levam um touro ao altar sacrificial, e, no momento do sacrifício, em lugar do sangue animal saiu um sumo retinto e sinistro; o sacerdote, Arrunte, consulta as divindades e aterroriza-se com o resultado das predições divinas: um nefas há e os deuses relevam isso no próprio ritual.

O simbolismo do fígado dividido em duas partes, uma putrefata e outra em atividades hepáticas normais, representa exatamente o caos autodestrutivo oriundo da Guerra Civil, que se estabelece como um combate fratricida; constatamos ser esta uma imagem subversiva, visto que a parte purulenta do fígado funciona vigorosamente e a parte normal está estagnada, conforme vemos: "E a própria coloração assustou o vate, uma vez que as pálidas vísceras/ estavam impregnadas com repugnantes marcas, e tingidas com gélida bile,/Espessa lividez do sangue variava com os salpicos..." (LUCANO, I, v. 618-620) ${ }^{26}$.

Todos esses fatores de contraversão social causaram a autorruína e levaram ao seguinte veredicto: Roma não pôde carregar-se (v. 72) ${ }^{27}$. A reviravolta causada pela Guerra Civil foi cataclísmica, determinando "o fim da República e a instauração da nova ordem imperial [que], à primeira vista, não ia de encontro às tendências culturais do principado de Nero" (VIEIRA, 2018, p. 5, grifos nossos). Isso fica tão evidente que, quando fugiam de Roma, os sacerdotes, senadores e civis vaticinavam o efeito nocivo dessa guerra fratricida e referendava o veredicto de que "nem Roma pôde suportar a si mesma", dada a gravidade dos rumos que Roma tomou. De fato, conforme afirma Vieira (2018), a Farsália se consolidou, no âmbito da tradição literária latina, como um texto épico que não se propõe a cantar um ato

\footnotetext{
${ }^{25}$ Vale salientar que Arrunte era o sacerdote de Baco. Desse modo, ele está inserido no seguinte contexto: "os sacerdotes - em número de dois na época do império romano - eram escolhidos em caráter vitalício; eles pertenciam aos honoráveis da cidade, pois deveriam custear com seus próprios bens uma grande parte das despesas, como animais para o sacrifício, incenso e construções, que configuravam um grande encargo nos tempos mais pobres da Grécia" (GIEBEL, 2013, p. 15). Por isso, Arrunte, na Farsália, é responsável por dirigir orações a Baco e por conduzir o "touro de cerviz eleita" (LUCANO, I, v. 608, tradução nossa).

${ }^{26}$ Versos originais: "Terruit ipse color vatem: nam pallida taetris/Viscera tincta notis, gelidoque infecta cruore/ Plurimus adsperso variabat sanguine livor".

${ }^{27}$ Cf. Nec se Roma ferens (v.72). Apesar de o verbo Ferens ser o particípio presente de Fero, optamos traduzir por uma estrutura perifrástica com infinitivo reflexivo, objetivando mostrar que a própria Roma foi a responsável pela cataclísmica destruição decorrente das conquistas territoriais e da agregação/assimilação de povos não latinos.
} 
digno de ser celebrado, mas como "um canto de repúdio à guerra fratricida que instaurou o principado, forma de governo autoritário, repressor e terrorista centrado num autocrata" (VIEIRA, 2018, p. 7).

\section{CONSIDERAÇÕES FINAIS}

Portanto, observamos, durante a realização desse artigo, que as imagens da subversão do direito se difundem a partir dos contextos social, político e religioso, como percebemos nos excertos que analisamos. Confirmamos essas hipóteses por meio dos seguintes pontos: a Farsália, narrada por Lucano, mostra, de forma literária, as imagens de reverberações sociais da supressão do direito, de modo que os fatos narrados não se encaixam apenas no âmbito da realidade, mas aparecem na interface com o ficcional. Sendo assim, podemos afirmar que há um viés de leitura possível que mostra a presença da subversão do direito na literatura grecolatina, entre humanos e deuses, bem como essas imagens se presentificam no texto de Lucano.

Constatamos, também, que a Farsália se diferencia das formas de subversões do direito encontradas em outras epopeias, pois, nela, a subversão se dá nos âmbitos cívico e político, pelas atuações dos homens, enquanto na origem dos deuses, estes participam do processo de subversão. Isso marca a diferença de abordagem do tema nos épicos supracitados, além de outras marcas de diferença, como: estilo linguístico, época e forma (oral/escrita) da produção, contexto histórico, noção de autoria, conteúdo interno, entre outras.

Vale salientar, ainda, que a presença de aspectos religiosos não influencia muito o ordenamento narrativo empreendido por Lucano, o que, de certa forma, pode justificar o emprego simbólico da pátria na epifania, no lugar do aparecimento de uma divindade, como ocorre geralmente nas narrativas épicas greco-latinas; supomos, pelas leituras, que esse fenômeno se estabelece pelas mudanças das virtudes e da mentalidade, uma vez que não estamos em uma ambientação do período arcaico, por exemplo.

Por fim, as imagens selecionadas para essa análise pertencem ao âmbito simbólico, o que nos permite inferir que há uma tripla inserção delas em planos distintos: o social, o simbólico e o literário. O plano social, que trata as realidades evidenciadas na Guerra Civil, retratada por Lucano, como um fato histórico, dada a pungência da disputa entre César e Pompeu. O plano simbólico, figurado pelas recorrências das imagens que suscitam essa ideia da subversão do direito no texto literário. E o plano literário - pois todos esses eventos são abordados como categorias literárias narrativas, pertencentes à esfera ficcional, a exemplo de: o episódio da epifania da pátria a César ser marcada por uma linguagem performática, como a 
caracterização das personagens, a imagem típica da ação, adjetivação, uso da personificação como recurso estilístico, entre outros.

\section{REFERÊNCIAS}

ALVES, José Carlos Moreira. Direito romano. Rio de Janeiro: Forense, 2018.

COULANGES, Fustel de. Cidade antiga. Tradução: Frederico Ozanam Pessoa de Barros. São Paulo: Editora das Américas, 2006.

GARCIA, Francisco Proença. O fenômeno subversivo na atualidade: contributos para o seu estudo. Revista Nação e Defesa, São Paulo, v. 3, n. 114, p. 169-191, 2006. Disponível em: https://www.idn.gov.pt/publicacoes/nacaodefesa/textointegral/NeD114.pdf. Acesso em: 13 out. 2019.

GIEBEL, Marion. O oráculo de Delfos. Tradução: Evaristo Pereira Goulart. São Paulo: Odysseus, 2013.

GRIMAL, Pierre. Dicionário da mitologia grega e romana. 7. ed. Tradução: Victor Jabouille. Rio de Janeiro: Bertrand Brasil, 2014.

HESÍODO. Teogonia. 3. ed. Tradução: J. A. A. Torrano. São Paulo: Editora Iluminuras, 1995.

HOMERO. Ilíada. Tradução: Frederico Lourenço. São Paulo: Companhia das Letras, 2013.

LUCANO. Guerra civil, livro 1. Tradução: Hermes Orígenes Duarte Vieira. João Pessoa: Ideia, 2018.

MARCONI, Marina de Andrade. LAKATOS, Eva Maria. Fundamentos de metodologia científica. São Paulo: Atlas, 2017.

OVÍDIO. Metamorfoses. Tradução: Domingos Lucas Dias. São Paulo: Editora 34, 2017.

ULLMANN, Reinholdo Aloysio. Filosofia da natureza nos estoicos. Revista de Filosofia Unisinos, Rio Grande do Sul, v. 9, n. 1, p. 5-11, jan/abr., 2008. Disponível em:

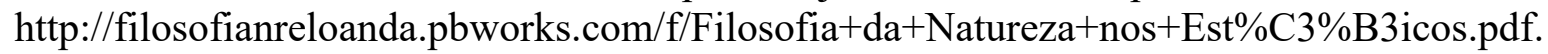
Acesso em: 07 jul. 2020.

VIEIRA, Hermes Orígenes Duarte. Tradução, introdução e notas do livro I da Guerra Civil de Lucano. João Pessoa: Ideia, 2018.

VIRGÍLIO. Eneida. Tradução: Carlos Alberto Nunes. São Paulo: Editora 34, 2016. 